\title{
LA SOBRE-INFANTILIZACIÓN DE LA INFANCIA: UN PROBLEMA PARA TODOS
}

Claudia Yarza ${ }^{1}$

\section{INTRODUCCIÓN}

Existe en América Latina una experiencia novedosa que discute la mirada de Occidente sobre la infancia, que se autoproclama como movimiento social, que nuclea en su seno organizaciones de niños, niñas y adolescentes trabajadores, y que plantea la necesidad de un cambio de paradigma hacia el del "protagonismo infantil".

No se trata de iniciativas para defender los derechos de los niños, tan importantes en la historia, en la pedagogía crítica, etc., ni de espacios donde se les da la posibilidad de decidir (por ejemplo el aula, los centros de estudiantes o los parlamentos infantiles), sino de movimientos sociales que surgen como autoorganización desde los propios niños, quienes articulan sus objetivos, crean normas y estructuras y son ellos quienes tienen la última palabra (LIEBEL, 1997, p. 30). Cuando surgió la primera organización en 1975 en Perú, estos niños -provenientes no de los estratos privilegiados y letrados sino de los que viven en la pobreza y en la lucha por la supervivencia, cosa que asumen de la manera más corriente desde muy temprana edad-establecieron que su organización no debía ser apéndice de ninguna otra organización ni debía ser representada por adultos (CUSSIÁNOVICH, 1997, p. 12). Desde entonces hasta hoy, viene creciendo un movimiento social latinoamericano que nuclea múltiples organizaciones, que envían sus delegados a convenciones, campamentos y talleres nacionales, regionales e internacionales, que tiene una agenda internacionalista y que vela por la cosa más sencilla del mundo: ser escuchados, ser respetados, ser considerados como parte integrante de la sociedad, no en general sino en particular en sus vidas concretas.

Si se quiere hacer algún tipo de analogía ideológico-política, las raíces del sindicalismo o el anarquismo están cerca de estas organizaciones, incluso de los movimientos de derechos humanos, por la manera en la que piensan al Estado, es decir, en la que disputan al Estado. Sin embargo hay que tener en cuenta que el discurso de los derechos, tan importante desde la Convención sobre los Derechos del Niño de 1989, es un discurso ajeno a la genealogía del movimiento, que es previa. De

\footnotetext{
${ }^{1}$ Facultad de Ciencias Políticas y Sociales, Universidad Nacional de Cuyo (Argentina). mcyarza@gmail.com
} 
hecho, que sean considerados sujetos de derechos, o que su situación pueda mejorar por la vía legal, son conclusiones a las que han llegado los adultos; el pensar y hablar en categorías jurídicas ha sido introducido por adultos a los movimientos de niños y adolescentes, sobre todo por aquellos educadores que se preocupan y conocen sus situaciones. Según Manfred Liebel, estos adultos de cierta manera han convencido a los niños que el hecho de referirse a sus derechos les puede ser de gran utilidad. Y los niños se han apropiado de este vocabulario (1997, p. 34).

Pero hay que tener muy en claro que sin los movimientos de los propios niños estas declaraciones y legislaciones quedarían como normas abstractas, y los niños como dependientes siempre de la buena voluntad de los adultos y de las instituciones. Porque lo que ellos ponen en cuestión es la mirada adultista: les importa jugar un papel activo, actuando como sujetos sociales en la consecución de sus derechos, y no esperando ser traducidos por los adultos. (LIEBEL, M.; MARTINEZ MUÑOZ, M., 2009, p. 74).

La existencia de este movimiento pone en cuestión, en efecto, nuestro paternalismo, nuestros esquemas casi intuitivos sobre la protección y el cuidado, llamándonos la atención sobre la cercanía que tienen estas representaciones con formas sutiles y no tan sutiles de discriminación. Un intento similar operó en la filosofía: la deconstrucción, decía Jacques Derrida, permite poner en evidencia la solidaridad histórica y sistemática de conceptos y "gestos de pensamiento" que muchas veces se sustraen a la crítica, a la posibilidad de su contextualización, a mirarles más allá de la "clausura" (es decir, del sistema cultural) de la cual proceden y en la cual parecen tener total inteligibilidad (1996, p. 20). Y así, la oposición niño/adulto parece correr pareja con el par maduro/inmaduro, completo/incompleto, sin percibir que abonan el terreno para predicar, también como gesto naturalizado, que lo incompleto e inmaduro se convierten en subdesarrollado, incompetente, inferior, y así sucesivamente.

¿Hace falta un análisis más exhaustivo de estas correlaciones para reparar su uso en el racismo y la misoginia? Precisamente, en aquellas posiciones que se presentan como afán de protección pero contienen toda una incapacitación encubierta. Como si el adultismo fuese la base de todas estas representaciones, ya que los negros, los indios, las mujeres, son vistos como necesitados, incompletos, irracionales, inmaduros, es decir, como niños.

¿Y será solo casualidad que este paternalismo dañino coincida con la mirada colonial europea, justamente la que inauguró la modernidad occidental? No nos asombremos de tener, en nuestra sociedad, prácticas coloniales hacia los niños: interpretando las diferencias en detrimento de su reconocimiento como sujetos sociales, económicos y políticos, practicando la protección como 
incapacitación, exponiéndolos siempre a la sospecha, al examen y no al reconocimiento, imponiéndoles regulaciones cada vez más "microfísicas".

Por eso, decimos, la existencia de estos movimientos, de estas reivindicaciones de la capacidad subjetiva de los niños, nos plantea preguntas filosóficas, éticas y políticas. En este trabajo, meramente exploratorio, fijaré la atención en algunos pasos o tópicos que considero se encaminan en la senda de estas preguntas.

\section{QUIÉN NECESITA A QUIIÉN}

He sugerido que hay un proceso de sobre-infantilización, muy ligado a la imagen culturalmente hegemónica de niñez, pero con matices diferenciales importantes. Por un lado, la modernidad - esa que luego erigió instrumentos como los derechos del niño- al separar lo público y lo privado creó mayor dependencia para los niños al atarlos a un rol pasivo, de mera preparación para la vida adulta, y de ocultación en el espacio privado y doméstico. Espacio cerrado y reducido, que potencia los mecanismos de sometimiento que convierten la infancia en el espacio para afianzar estereotipos y violencias.

Pero este paternalismo peculiarmente duro convive hoy con otras formas de paternalismo. El niño actual, estimulado por la propaganda y el consumo, ya no pertenece a ese mundo cerrado y reducido, y sin embargo sigue siendo igualmente confinado a un rol pasivo y dependiente, y de un tipo de pasividad tan fabricada, tan poco "natural", tan heterónoma. Niños que difícilmente podrían pensarse ya como sujetos, o cuyo papel y rol está cada vez más ceñido, más ajustado a lo que el mundo desea para ellos: que sean en el futuro, nuestro futuro.

Decía Walter Benjamin en un breve texto: "la burguesía ve en su prole al heredero; los desheredados ven en la suya auxiliadores, vengadores, liberadores" (1989, p. 110). Recuperar esta perspectiva, que para el berlinés era parte de una "pedagogía comunista", significa percibir en las infancias una rigurosa capacidad, una potencia, una posición subjetiva que no es reflejo, copia ni reproducción, que no se deja reducir ni cortar al talle de "nuestro" futuro, sino que contiene la posibilidad de diseñar su mundo transformando lo recibido (GUIDARELLI, 2015).

Y en efecto, podríamos pensar que si los niños nos necesitan, dadas sus potenciales vulnerabilidades naturales, nosotros los necesitamos más aún. Incluso desde el punto de vista de la reproducción del sistema, ya que para reproducir el futuro que les hemos diseñado necesitan ser, ser potentes y ser capaces, lo cual encierra toda una contradicción. Por eso es mejor prescindir de ese 
razonamiento teleológico y utilitarista, y en cambio preguntarnos ¿quién ayuda a quién? ¿Quién protege? ¿Qué protegemos, qué reproducimos con nuestros mecanismos de protección? La sobreinfantilización de la infancia a la que intento referirme puede ser el último mecanismo antiantropogenético por excelencia, la anulación -por la vía de una individualización cada vez más microdisciplinaria- de toda potencia, la generación de individuos fragmentados, separados, anestesiados, cada vez más necesitados de tutela.

¿Estamos en la senda de percibir este escollo? ¿No debiéramos, en todo caso, invertir el esquema y pensar en la genealogía de nuestros propios perfiles de deshumanización, para los que el adultismo juega un papel tan funcional? ¿Entre quiénes se verifica realmente la mengua en la capacidad, si no en el modelo de desubjetivación (en tanto depotenciación) que nos impone -a todas y todos- la sociabilidad hoy dominante? Y finalmente, ¿quién -o mejor, qué cosa- dentro de nosotros se satisface con el plus de goce de una autoridad infundada, infructuosa y autodestructiva?

\section{DE DÓNDE SALEN LOS SUJETOS}

La fórmula benjaminiana es exitosamente neutralizada por la sociedad burguesa; muy a contramano de su filosofía política y de su ética cívica, hoy lo que más se percibe de nuestras formas de sociabilidad es la suspensión de lo que la política tiene de libertario y de autogobierno, mientras campea lo que a partir de Foucault comenzó a pensarse como "gubernamentalidad" liberal, verdadera clave interpretativa para el tipo de racionalidad que se escabulle detrás de la ciudadanía y el derecho (2007, p. 359 y ss., 2006, p. 136 y ss.). Foucault ciertamente introdujo el análisis de lo policial/funcional/disciplinador en los espacios de poder que acompañaron el crecimiento del capitalismo y del mercantilismo. Verdadera “corrosión” de lo político, este proceso fue trabajado por Foucault en distintas fases. Inicialmente, sus análisis permitían desentrañar la existencia de mecanismos locales y empíricos que explicaban la conformación de cuerpos dóciles y útiles, gobernables, disciplinados. De esta primera etapa, donde concibe esa especie de anatomía política que creaba sujeciones y gestionaba conductas, Foucault pasó a otro nivel, que no niega el anterior sino que expande su campo: ya no tanto la disciplina aplicada a los cuerpos, sino los dispositivos de regulación aplicados a toda la sociedad, o mejor dicho, a la "población". El pasaje supone lo que llamará "biopoder" o biopolítica, término que permite comprender ese tipo de "gestión" cuyo objeto es la población tomada como una masa a la que se debe cuidar, hacer crecer o regular: la seguridad del conjunto respecto a sus peligros internos. Con agudeza, hoy los estudios poscoloniales y decoloniales han agregado una nota al pie de este análisis foucaultiano: no habría biopolítica sin 
historia colonial, sin la mirada "inferiorizante" que la colonización fijó sobre los colonizados, en adelante masas humanas desprovistas de humanidad puestas como recurso, como materia (incluso como paisaje, dirá Fanon), como mero espacio disponible para la explotación (MBEMBE, 2011; FANON, 2015; GEBARA, 2007; MALDONADO TORRES, 2007).

Decimos corrosión de lo político, porque en efecto, este escenario no es campo fértil para la emergencia de los vengadores y liberadores. Dirá Jacques Rancière: ninguna cosa es política esencial o paradigmáticamente; en todo caso, cualquier cosa puede llegar a ser política si es capaz de atravesar lo "policial" dado, la distribución, la identificación de cada porción de lo social con su parte. En otras palabras, si la política es asunto de sujetos, no los crea ex nihilo, sino cuando transforma identidades antes definidas como partición "natural" del orden social (funciones, lugares) en instancias de litigio (RANCIÈRE, 1996, p. 51). Si el orden (pospolítico, biopolítico o antipolítico) confina a cada uno a la presentificación de "su" identidad y "su” demanda, por el contrario, la subjetivación política es como una desidentificación, el arrancamiento a la naturalidad de un lugar, la apertura de un espacio de sujeto donde cualquiera puede contarse.

¿Por qué, si no, suena tan escandaloso hablar de los niños como sujetos políticos? ¿Por qué tendemos a asumir que esa fórmula debiera portar un equívoco, y que como dicen las instituciones educativas ellos deben formarse antes en la sociabilidad liberal individualizante para que en el futuro sean ciudadanos? ¿Por qué, finalmente, ellos resisten esta tergiversación?

Aunque la política se da rara vez, o no se da en absoluto, cuando sí lo hace es sobre el trasfondo de un suelo policial, o sea estatalizado, institucionalizado, distribuido, gestionado, disciplinario. La escena polémica es escena paradójica, "al postular existencias que son al mismo tiempo inexistencias, o inexistencias que son a la vez existencias" (RANCIÈRE, 1996, p. 59).

\section{VOLVER PROBABLE AL SUJETO}

¿Cómo no ver la mezcla de esa mirada moral y policial, tutorial y utilitaria, que distribuye roles y funciones, por ende infantilizadora/paternalista, en las propias instituciones modernas (educativas, sexuales, políticas, jurídicas, económicas, sanitarias etc.)? ¿Qué grados de potencia o de impotencia subjetiva resisten estas estructuras - hoy sutiles, por la invisibilidad y la naturalidad de las cuales se invisten?

Michel Foucault asimiló biopolítica y liberalismo en sus últimos cursos del Collège de France. Él señalaba que el poder no coacciona ni reprime, sino que produce discursos, cuerpos e instituciones; los produce y luego los distribuye en dominios de valor y de utilidad. ¿Cómo lo hace? la fórmula que 
destaca Deleuze, traduciendo un poco a Foucault es: "volver probable" (DELEUZE, 2014, p. 84). El poder no es pura violencia instrumental, eso no ayuda a entender nada. Es incitar, inducir, facilitar o dificultar, ampliar o limitar, volver más o menos probable. Es aumentar las aptitudes de la vida en los cuerpos individuales según la anatomopolítica, y regular la población biopolíticamente, ajustándola a fenómenos económicos de conjunto. No libera ni coarta, sino que intensifica la vida que se produce y administra en sus propias tecnologías. Y esto lo hace de una manera "liberal"; en efecto, el liberalismo para Foucault no es una ideología sino una tecnología de poder, y la libertad (una peculiar versión de ella) es un mecanismo de esa tecnología (2006, p. 71). No se trata de aceptación ni respeto de cierta libertad previa, sino de prácticas que "liberan" cuerpos respecto a otras formas de lazo social, lo desatan, lo ponen en circulación, y así biopolíticamente vuelven probables la competencia y todo lo que ésta conlleva -incluido lo que Frantz Fanon denominaba "la forma atea de la salvación": la indiferencia hacia los demás (FANON, 1972, p. 42).

Si hay una mano invisible que guía la conformación de nuestra sociabilidad, una conducción biopolítica (Foucault), policial (Rancière), administrativa-tutorial-paternalista, lo hace de una manera ciertamente difusa, mediante unas tácticas de poder que son pequeñas sanciones, pequeños desvíos, incitaciones (FOUCAULT, 2006, p. 403), con lo cual instalan lo probable, lo admitido, lo "normal", como la subjetividad mercantil, el individualismo, incluso la actitud misántropa de los héroes del consumo, que no se desalientan entre nuestros jóvenes, sino todo lo contrario. Y colocan al margen lo menos útil y dócil, volviendo menos probable aquello que nos hubiera permitido resistir la subordinación de lo humano a esas dinámicas ineluctables, a esos nuevos dioses que se tragan nuestra humanidad.

El desarrollo del 1lamado "giro decolonial”, sobre todo en América Latina, está enderezado a visibilizar los velos epistémicos que naturalizan esos "gestos de pensamiento", como decía Derrida, que se imponen sustrayéndose a la crítica, ocultándose. Y sobre todo apuntala el rescate de aquellos saberes sojuzgados, aquellas experiencias que hicieron probable una capacidad de resistencia. Capacidad que se halla, no tengamos duda sobre ello, en el suelo relacional-cultural-afectivosubjetivo-político capaz de volver probable otra modalidad del ser juntos humano.

Quizás la pertenencia a América Latina, nacida y propiamente nombrada como periferia como afirma Enrique Dussel- nos permita incluso más chances de des-infantilizarnos, porque entre nuestros pueblos el lazo social no se reduce (aún) al modelo de la ciudadanía liberal, como muestran hoy el ecofeminismo, el feminismo comunitario, y el llamado paradigma del protagonismo infantil, todos los cuales son sólo ejemplos de unas prácticas capaces de resignificar las exclusiones epistémicas, culturales, de género, de raza. Este diálogo está en movimiento, y representa una 
auténtica novedad en el llamado Sur global, porque integra el rechazo de las emanaciones conceptuales de la propiedad -la afinidad de la mirada patriarcal, androcéntrica, colonial y adultista sobre el cuerpo de las mujeres, los niños, la naturaleza- con una reflexión sobre la vida, la humanidad, el poder.

\section{REFERENCIAS:}

BENJAMIN, W., "Una pedagogía comunista” en Escritos. La literatura infantil, los niños y los jóvenes. Buenos Aires: Nueva Visión, 1989, pp. 109-112.

CUSSIÁNOVICH, A. "Del olvido a una emergente visibilidad social de la organización de los NATS en América Latina", en VVAA, Niñ@s trabajadores. Protagonismo y actoría social, [s.1.] Ifejant, 1997, pp. 7-28. 1 CD-ROM

DELEUZE, G. El poder. Curso sobre Foucault. Buenos Aires: Cactus, 2014.

DERRIDA, J. De la gramatología. Traducción de Oscar del Barco y Conrado Ceretti. 4 ed. México: Siglo XXI, 1996.

DUSSEL, E. "Europa, modernidad y eurocentrismo", en Hacia una filosofía política crítica. Bilbao: Desclée de Brouwer, 2001, pp. 345-358.

FANON, F. Los condenados de la tierra. Traducción de Julieta Campos. 2 ed., 3 reimp. México: FCE, 1972.

FOUCAULT, M. Nacimiento de la biopolítica. Curso en el Collège de France (1978-1979). Traducido por Horacio Pons. Buenos Aires: FCE, 2007.

FOUCAULT, M. Seguridad, territorio, población. Curso en el Collège de France (1977-1978). Traducido por Horacio Pons. Buenos Aires: FCE, 2006.

GEBARA, I. "Reflexiones desde el ecofeminismo", Revista teológica de la Universidad Bíblica Latinoamericana, Volumen 27, №1, San José, Costa Rica, 2007.

GUIDARELLI, R. "Los herederos: hacia una crítica benjaminiana de la infancia” ponencia en Coloquio Teoría Crítica desde las Américas, Querétaro, 2015 (en prensa).

LIEBEL, M. "NAT's organizados y derechos de infancia” en VVAA, Niñ@s trabajadores. Protagonismo y actoría social, [s.l.] Ifejant, 1997, pp. 29-47. 1 CD-ROM.

LIEBEL, M.; MARTINEZ MUÑOZ, M. (coords.), Infancia y derechos humanos. Hacia una ciudadanía participante y protagónica. Lima, Ifejant, 2009. 1 CD-ROM.

MALDONADO TORRES, N. "Sobre la colonialidad del ser: contribuciones al desarrollo de un concepto", en CASTROGOMEZ S.; GROSFOGUEL R. (eds.), El giro decolonial. Reflexiones para una diversidad epistémica más allá del capitalismo global. Bogotá: Siglo del Hombre, Universidad Central, Pontificia Universidad Javeriana-Instituto Pensar, 2007, pp.127-167.

MBEMBE, A. Necropolítica. Traducción de Elisabeth Falomir Archambault. España: Melusina, 2011.

RANCIÈRE, J. El desacuerdo. Política y filosofía. Buenos Aires: Nueva Visión, 1996. 


\section{LA SOBRE-INFANTILIZACIÓN DE LA INFANCIA: UN PROBLEMA PARA TODOS}

Resumen

El trabajo toma como eje la crítica al adultismo que ha sido expresada por una experiencia de organización de niñas, niños y adolescentes que en América Latina se denomina "protagonismo infantil". Adultismo y paternalismo, sin embargo, pueden ser relacionados con la colonialidad que introdujo una incapacitación sobre indios, mujeres, negros; por ende, con una microfísica del poder, fruto de la modernidad, que es tendencialmente global y llega, bajo la forma hoy dominante de la gubernamentalidad, a una infantilización de los ciudadanos y correlativamente, a la corrosión de la subjetividad y la política.

Palabras clave: protagonismo infantil - adultismo - gubernamentalidad

\section{A HIPER-INFANTILIZAÇÃO DA INFÂNCIA: UM PROBLEMA PARA TODOS}

Resumo:

O trabalho toma como eixo a crítica ao adultismo, que foi expressada por uma experiência de organização de crianças e adolescentes que na América Latina se denomina "protagonismo infantil". Adultismo e paternalismo, no entanto, podem ser relacionados com a colonialidade que introduziu uma incapacitação sobre os indígenas, mulheres e negros; portanto, com uma microfísica do poder, fruto da modernidade que é tendencialmente global e chega sob a forma hoje dominante da governabilidade, a uma infantilização dos cidadãos e, correlativamente, à corrosão da subjetividade e da política.

Palabras-chave: protagonismo infantil - adultião - governamentalidade

\section{THE OVER-INFANTILIZATION OF CHILDREN: A PROBLEM FOR US ALL}

Abstract:

The work takes as its axis the critique of adultism that has been expressed by an experience of organization of children and adolescents that in Latin America is called "children's protagonism". Adultism and paternalism, however, may be related to the coloniality that introduced incapacitation on Indians, women, blacks; therefore, with a microphysics of power, the fruit of modernity, which is tendentially global and, under the current dominant form of governmentality, comes to an infantilization of the citizens and correlatively, to the corrosion of subjectivity and politics.

Key words: "children's protagonism" - adultism - governmentality 